O SR. WALDEMAR FERREIRA - Vamos proceder à votação. Para facilidade do trabalho vou tomar, primeiro, os votos dos que votam a favor, e depois dos que votam contra.

Os Congressistas inscritos que aprovam as conclusões tenham a gentileza de se levantarem.

Está aprovada a conclusão do relatório relativamente à primeira proposição.

Vou submeter a votos as outras duas conclusões do relatório do professor Hernani Estrella, relativamente à proposta do professor Perrotta. Uma é no sentido de que a questão relativa ao crédito bancário confirmado o Congresso recomende seja estudada por um Congresso Internacional, prefentemente latino-americano, que examinará, então, as possibilidades de sua adoção pelas leis dos diversos países. Os que aprovam esta conclusão queiram se conservar sentados. (Pausa) Aprovado.

A terceira conclusão é a seguinte que, “diante da proposta no sentido de que o Congresso recomende a adoção dos votos múltiplos nas ações das sociedades anônimas, o parecer é contrário a esta proposição, pela razão de que existe lei no Brasil contrária também a esta mesma proposição, e está de acôrdo com a doutrina mercantil brasileira.

Os que votam pela conclusão, queiram ficar sentados. (Pausa).

Está aprovado o parecer.

Estamos com a nossa hora adiantada. Quero, em primeiro lugar, agradecer aos prezados colegas e aos Congressistas o seu comparecimento a esta sessão. Em segundo lugar, quero felicitar aos que debateram as teses que se apresentaram e também aos que as debateram nas comissões. Isto nos demonstra que é muito vivo e por isso mesmo muito cintilante o espírito jurídico dos meus prezados amigos e patrícios do Rio Grande do Sul.

Faço votos que continuem os nossos trabalhos com êste mesmo brilho, porque isto será um bem e um prazer, afinal de contas, para nós. Está encerrada a sessão.

\section{COMUNICACION AL CONGRESSO JURIDICO CONMEMORATIVO DEL CINCUENTENARIO DE LA FACULTAD DE DERECHO DE RIO GRANDE DEL, SUD - (Brasil)}

\author{
SOBRE: ACTOS DE COMERCIO.
}

\section{Waldemar Arecha}

Profesor Adjunto de Derecho Comercial en la Facultad de Derecho de Buenos Aires. Profesor Adjunto de Sociedades Anónimas y Seguros en la Facutad de Ciencias Económicas de Buenos Aires.

Las tentativas de reformar el Código de Comercio en cualquier país no deben perder de vista un punto de partida primario y necesario para que la reforma resulte provechosa y ordenada.

Entiendo que todos los afanes y esfuerzos que se presten para la reforma y perfeccionamiento de las múltiples instituciones del derecho mercantil, no serán bastantes si no se cuida de que los principios básicos o rectores que determinen la importapcia y el ámbito mercantil estén perfectamente ordenados y expuestos en el curepo orgánico de leyes (Código) que se pretende reformar.

Es pues evidente, que el mayor cuidado de la reforma debe estar - para que el cimiento sea sólido - en lo atinente al acto de comercio. $\mathrm{Y}$ que no se debe eludir de tratar esta cuestión en virtud de las dificultades que élla of rezca.

Si toda la autonomía del derecho mercantil, o por mejor decir, su propia existencia radica - valga la paradoja - en la afirmación consciente de que existe la materia mercantil, es indudable y fundamental que élla debe ser enunciada y no dársela por supuesta. Esto último comporta dejar abiertas las puertas para que se presenten ulteriores confusiones del ámbito civil y del derecho mercantil, y para que toda la arquitectura de la reforma pueda sentirse invadida de elementos extraños, o pueda a su vez invadir otros ámbitos que no sean los propios.

Para abordar la tarea de enunciar el ámbito mercantil es necesario olvidar los clássicos puntos enunciativos o enumerativos del Código de Napoleón y de los que lo subsiguieron, lo mismo que la 
corriente puramente profesional y personalista del Cốdigo Alemán en la que también se halla hoy el Código del Brasil.

Si estamos totalmente de acuerdo en que el acto de comercio puro y sustantivo es el que se presenta por la intermediación en el campo. de la circulación de las cosas (quien adquiere para revender, usando de las cosas como valores de cambio según la doctrina de Adam Smith) vemos que hay alli una actividad técnica, que se caracteriza precisamente por esa intermediación como actividad técnica, caracteristica. y autónoma.

Es ese fenómeno de la intermediación el que luego transciende, arrastrando sus características mercantiles, que se configuraron en las corporaciones de comerciantes $\mathrm{y}$ en el derecho estatutario medioeval, a otros sectores de la humana actividad: así la intermediación en el cambio de riesgos, que da la presencia de la compañia aseguradora suplantando a la mutua en la que se operaba la comunicación directa. de los riesgos entre los mutuarios; la intermediación en el cambio del crédito, la que se manifiesta por la aparición del banquero que recoge las prestaciones de los dadores de dinero para colocarlas entre los solicitantes del numerario; y la intermediación en el trabajo, que manifiesta y pone de relieve la presencia de un sujeto (generalmente empresario) que hace que los dadores del trabajo no reciban el resultado. de su esfuerzo sino un signo convencional por el mismo.

Resta otra especie de actividad: la industrial o de fábrica. La actividad industrial no aplicada enfrente de la Naturaleza es, como la actividad del comerciante, una actividad extraña a la relación que la Naturaleza le presentó ai individuo. El empleo de los valores industriales (más adelante explicamos nuestra doctrina sobre esto) en el despliegue de esa actividad, dá a las cosas un destino técnico que se interpone a su destino natural. Es decir, se opera en ellas el mismo fenómeno técnico que se opera cuando interfiere el comerciante en la circulación de las cosas salidas de manos del productor en su subsiguiente tránsito antes de alcanzar las manos del consumidor.

Los valores industriales (así como los valores de cambio), no son un estado esencial de las cosas ni que se acuse por la naturaleza de las propias cosas. Las cosas pueden convertirse en valores de cambio (según la clásica doctrina de Adam Smith) por quedar aplicadas. como portavalor por un sujeto, sin que muden su naturaleza. Las cosas pueden ser valores industriales, en la doctrina del suscripto, por aplicárselas a una mudanza del destino inmediato de consumir o acabar la propia cosa por su consumo natural, destinándola en cambio a transformarse, o transformar o unirse con otras, todo ello mediante un proceso de energía no natural (energía artificial), que no puede ser otra que la prestada por máquinas movidas a combustible o fluídos que no sean directos de la naturaleza.

Indudablemente la actividad agraria, que no es una actividad ejercitada enfrente de la Naturaleza, sino una actividad ejercitada "con la Naturaleza", desde que el hombre asiste al proceso que la Naturaleza opera metamorfosicamente, no sería nunca comercial. $\mathrm{Ni}$ puede hablarse en ella de que el empleo de máquinas movidas a combustible nos muestre esa actividad como comercial, porque en la actividad agraria la energía de la máquina nada transforma sino que es la propia naturaleza o fuerza interna de la propia cosa la que opera el proceso por si misma y sin la máquina (el grano de trigo, que podría ser un valor industrial cuando sirve para la fabricación de un plástico mediante energía artificial, no lo será jamás cuando se lo siembra, pues en el acto de sembrarlo lá máquina nada transforma sino que la transformación se operará luego por el propio vigor del grano y de la tierra, y tampoco hará ninguna transformación la máquina cosechadora que solo lo arrancará de su estado natural).

Esta doctrina ha sido presentada y desarrollada con mayor amplitud y fundamentos en mi obra "La Empresa Comercial" (Editorial Depalma, Bs. As., 1948), parágrafos N.o 43 a 52, páginas 94 a 116.

Con esas premisas podría sancionarse un artículo racional, desde el triple punto de vista técnico, jurídico y económico, que estableciese:

Art. 1.9 Constituyen actos de comercio la intermediación en la circulación de los bienes; la intermediación en el trabajo; la intermediación en el cambio de crédito; la intermediación en el cambio de eventos; y la aplicación de cosas como valores industriales.

$2 .^{\circ}$ Quedan sometidos a las leyes del comercio todos los negocios sobre los que legisla este código y las leyes complementarias.

3. Quedan también sometidas a las leyes del comercio todas las personas y sociedades sobre las que legisla este código y leyes complementarias.

Con el texto que formulamos todas las actividades hoy reputadas típicamente mercantiles quedarán comprendidas en la ley comercial.

Desaparecería con él la categoría arbitraria y caprichosa de actos formalmente mercantiles que, pese a su reiteración, no atribuyen carácter mercantil a quien los practique (tal el caso de la suscripción reiteradísima de cheques o pagarés) en abierta contradicción con lo que dispone la gran mayoría de los códigos de comercio, segun una muy sabia norma, por la cual la ejecución reiterada y habitual de actos de comercio hace o convierte en comerciante a quien los practica. En rigor de verdad esa sabia norma no es esquivada en tales 
easos singulares sino que es inaplicable a lo que no sea acto de comercio, como no lo es la suscripción de cheques, pagarés etc., aunque los códigos lo digan, porque los hechos, el reciocinio y la propia jurisprudencia se encargan de negarlo aunque sin esta explicación.

El texto que hemos proyectado no impediría que los actos que concurren a la vida y desenvolvimiento del comercio, como es la emisión de cheques y pagarés, sean enquiciados y juzgados conforme a las leyes mercantiles.

En cuanto a la circulación, preferimos hablar de bienes y no de valores. El primero es un concepto que se acerca más a la realidad; el segundo, está más próximo a la abstracción. El aire, por ejemplo, que es un bien, no es en cambio un valor, porque nada vale como aire por su infinita abundancia. Empero, ese mismo aire, comprimido, es susceptible de valor.

Excluímos en cambio el concepto de cosas, porque ha pasado la hora en que el comerciante operaba sólo sobre cosas, y hoy le vemos también traficar sobre derechos. Los derechos son también una forma de bienes.

Lo que hoy se llama especulación o lucro con el trabajo de otros, o lo que se pretende sostener de que el trabajo sea una mercancía, no sería menester sostenerlo para afirmar la actividad mercantil que se cumple mediante la intermediación entre los dadores y los tomadores de trabajo. Lo mismo sucedería con los negocios de banca, financiación, capitalización, etc. y también con los de seguro. $\mathrm{Y}$ por último con los de fábrica.

También sucedería que las sociedades del tipo de las que legisle el código de comercio serían juzgadas conforme a las leyes del comer cio, pero sus actos, aisladamente considerados, serían juzgados conforme a su propia y especial naturaleza.

\section{RELATÓRIO E PARECER}

\section{Relator: NEY WIEDMANN}

$\S 10^{\circ}$ - Estabelece o prof. Arecha a imprescindível necessidade de fixação dos princípios básicos ou orientadores, que delimitem o "âmbito mercantil", ou seja, qual é a matéria mercantil. Dá como ponto essencial aquêle referente ao "ato de comércio", cuja conceituação deve ser formulada, por mais difícil que se apresente.

Propõe se abandone o sistema exemplificativo, bem como o sis tema personalista. Isto pôsto, considera que "ato de comércio puro e substantivo" é o que se configura como "intermediação no campo da circulação das cousas": aquisição para revender, considerando as cousas como valores de troca. Existe, aí, uma atividade técnica, caracterizada e autônoma.

Nota que o fenômeno da intermediação especificou como mercantís as corporaçóes de comércio e o direito estatutário medieval; a intervenção em matéria de riscos (companhias seguradoras), em relação ao crédito (bancos), referentemente ao trabalho (empresário). Trata, com relêvo especial, da atividade industrial, encarando a utilização das cousas como valores industriais, e considera essa atividade idêntica - em essência - à atividade do comerciante que intervém na circulação das cousas. Exclui do âmbito comercial a atividade agrária: não se trata de atividade exercida "sôbre a Natureza", mas "com a Natureza". Neste passo, faz o autor referência a desenvolvimento e fundamentação, lançados em "La empresa comercial", §§ 43-52).

$\S 2 .^{\circ}$ - Propõe, em conseqüência, formulação de texto, que atenderá aos aspectos técnico, jurídico e econômico do "ato de comércio".

Fxamina a repercussão dessa fórmula sôbre os atos de comércio por fôrça da lei ("formalmente mercantiles"); explica o uso da expressão bens, em lugar de valores e cousas; mostra a desnecessidade do exame da existência de "especulação" ou "lucro", na intermediação no trabalho; e especifica o modo de aplicação da norma às sociedades de tipo regulado pela lei comercial, mas que pratiquem atos de outra natureza.

$\S 3 .^{\circ}-\mathrm{A}$ tese, apresentada pelo prof. Arecha, examina matéria sedutoramente atraente, mas consagrada como vexata quoestio. Parece-nos que não pode ser devidamente apreciada sem o exame dos de mais trabalhos do autor, onde mais detidamente são expostos os fundamentos da síntese de jure condendo, ora apresentada. Temos à mão aquêle indicado na tese - "La empresa comercial" —, onde foi formulada definição de ato de comercio:

"toda negociación que verse sobre bienes que sean valores de cambio de parte de la persona que los adquiere, y los actos subsiguientes de enajenación de esos mismos valores" (pag. 60).

Firma o autor que êsses atos não serão qualificados pela natureza ou identidade física da cousa, nem para isso servirá a profissionalidade da pessoa que interferir na operação (pag. 59).

Com êsses elementos, parece-nos que:

a) a norma proposta impossibilita a regulamentação comercial do ato misto (o ato inicial e $o$ ato final da atividade comercial), criando colisão de leis no seu enquadramento jurídico;

b) apesar de se negar relevância à profissionalidade da atividade do intermediário, essa circunstância se apresenta ponderável em se tratando, p. ex., de "troca de crédito"; 
c) há possibilidade de colisão de leis, em se tratando de atos praticados por sociedades civis, organizadas sob tipo comercial.

$\S 4 .^{\circ}$ - Em conclusão,

1) versando sôbre tema reconhecidamente eriçado de controvérsias, a tese apresentada, encarando-o lúcida e sintèticamente, se reveste da máxima relevância;

2) desbravando o conceito de ato de comércio de outros elementos (lucro, profissionalidade, etc.), a tese visa atingir à diferença específica dêsse ato;

3) merece ser recomendada a proposição oferecida, como valiosa contribuição para fixação dêsse debatido conceito.

\section{DEBATES EM PLENÁRIO:}

O SR. PRESIDENTE - Júlio César Bonazzola. - Está em discussão a tese de autoria do sr. Valdemar Arecha, sôbre "Actos de Comercio".

E' relator o sr. Ney Wiedmann, a quem concedo a palavra.

O SR. NEY WIEDMANN - 0 Professor Valdemar Arecha, tendo em vista possíveis reformas da legislação comercial, principalmente sul-americana, entende que seria conveniente fixar um princípio básico e orientador que pudesse delimitar o âmbito mercantil, estabelecer possivelmente qual é a matéria mercantil. Entende que é essencial fixar a noção de ato do comércio. Por mais difícil que pareça, sua conceituação deve ser pelo menos tentada.

Não admite êle como suficiente o sistema exemplificativo e não se filia ao método personalista. Considera que o ato de comércio êle chama de puro e substantivo - é aquêle que se configura como uma intermediação no campo da circulação das coisas, aquisição para revender, considerando as coisas no seu valor de troca. Entende que aí existe uma atividade técnica, caracterizada e autônoma.

Esta intermediação específica foi que tornou mercantil, segundo êle explana, todo ato das corporações do comércio no direito estatutário medieval. Sua intervenção na matéria de riscos deu origem às companhias seguradoras; em matéria de crédito deu origem aos bancos e, quando se tratou da intermediação do trabalho, apareceu então o empresário.

Examina êle ainda a intermediação que tem por objeto o emprêgo das coisas como valores industriais, as coisas que são usadas não para o consumo nem para a revenda, mas sim para poderem transformar, incorporar ou auxiliar a transformação de outras. Êsses serão os valores industriais.

Também chama a atenção para o fato de não se dever usar a expressão "valor" nem a expressão "coisas", mas usar sòmente a expressạ̃o "bens", como sendo menos abstrata, mais suscetível de interpretação econômica do que as outras duas.

Entende ainda que nunca se poderá incluir como atividade mercantil a atividade agrária. A atividade agrária, segundo êle, é aquela que se exercita "enfrente a la naturaleza" e não "con la naturaleza", em vernáculo, aquela que se exercita "sôbre a natureza" e não "com a natureza".

Com êstes elementos êle propõe que se considere ato de comércio a intermediação na circulação dos bens, a intermediação no trabalho, a intermediação na troca de crédito, a intermediação na troca de eventos, tôda aplicação das coisas como valores industriais.

Acrescenta uma alínea: ficarão submetidas às leis do comércio tôdas as pessoas e sociedades sôbre as quais legislarem êste código e as leis complementares.

E ainda outra:

Ficam submetidos às leis do comércio todos os negócios sôbre os quais legislar êste código e as leis complementares.

Esta tese encontra-se exposta em três fôlhas e meia, como os colegas vêem. Parece pouco espaço para tão complexa matéria. De modo que para compreendê-la bem, deveríamos ter em vista tôda a obra do professor Arecha, sob pena de não entendermos efetivamente os conceitos.

Eu procurei a definição que deu de ato de comércio no seu livro "A emprêsa comercial", em que diz que "é todo o negócio que versa sôbre bens que sejam valores de troca para pessoas que os adquirem e os atos seguintes de alienação dêsses mesmos valores".

Êle entende que a natureza ou entidade física da coisa não serve para caracterizar o ato de comércio. E tampouco serve a profissionalidade da pessoa que interfere na operação.

Resumindo, a idéia do professor Arecha é de que o primeiro ato de aquisição não é comercial e que o ato final de venda também não o é. Comerciais serão os atos de intermediação, de circulação da coisa; a revenda depois da primeira aquisição e a venda e revenda sucessivas é que formam a atividade comercial.

Sôbre isto construiu êle aquela noção de ato de comércio que propõe à consideração do Congresso, como elemento básico para as reformas futuras da legislação comercial.

Pareceu-me que esta concepção de ato de comércio como sendo apenas aquêle que existe entre o ato inicial, em que o valor de con- 
sumo é transformado em valor de troca, e o ato final, em que o valor de troca volta a ser ato de consumo, exclui, dentro do meu conceito, ao âmbito da regulamentação comercial, êste primeiro ato e aquêle último.

Nós teremos, em conseqüência, o ato misto inicial e teremos o ato misto final sujeitos a outra legislação. E' uma dificuldade prática, pelo menos, que a nossa legislação procurou resolver, sujeitando o ato misto, integralmente, à legislação comercial e o considerando como um ato de comércio, por fôrça da lei, pelo menos.

Contra êsses atos formalmente mercantis, ditados por fôrça de lei, o professor Waldemar Arecha também se insurge. Entende êle que não deva haver essa classificação de atos: ou serão todos referentes à intermediação ou, se não forem referentes à intermediação, não serão atos de comércio. Exemplificando, diz que a nota promissória e as cambiais usadas pelo comerciante serão atos de comércio. Notas promissórias e letras de câmbio usadas pelos particulares não serão atos de comércio.

Nós temos aí, novamente, uma complicação, que o nosso Direito procurou resolver com $o$ ato comercial por fôrça de lei.

Além disso, admitindo como ato de comércio a intermediação de valores, a intermediação de crédito pròpriamente, especificamente, e repelindo a profissionalidade como característica do ato de comércio, parece-me que as emprêsas bancárias ficam numa situação dúbia, porque para que haja um banco é necessário a sua profissionalidade. Excluindo a profissionalidade, nós não poderemos entender a atividade bancária, como sujeita à lei comercial e às leis complementares, como sociedades sôbre as quais legisla êste conjunto de leis comerciais. Nós teríamos, então, aquela difusão de sociedades comerciais, simplesmente pelo tipo que adotaram, sociedades essas que, segundo êle explana, serão reguladas pela lei comercial quanto ao seu funcionamento, mas, nos seus atos específicos, nas suas atividades próprias, serão reguladas pela lei civil.

E, evidentemente, um outro aspecto em que o conceito restrito de ato de comércio, usado por êle, cria alguma confusão. Mas, excluindo da conceituação dada ao comércio o conteúdo de lucro, excluindo a profissionalidade, e aceitando apenas esta conceituação de intermediação, que melhormente nós diremos que é uma conceituação de emprêsa, o professor Waldemar Arecha formula um conceito de ato de comércio restrito, mas que dá uma base certa para dêle se partir. Ele, criando aquela situação que eu explanei, nos dá, em todo o caso, essa base . E daí se pode partir para esclarecer o âmbito mercantil, já com uma base acertada.

$O$ autor apresenta-se evidentemente lúcido e sintético e se mostra encarando um assunto de máxima relevância. Com êsse afasta. mento de vários elementos que nós consideramos como essenciais ao ato de comércio, procura atingir a uma diferença específica. Eelo menos, a fixação de um ponto que se pode considerar devidamente alcançado.

Em conseqüência, merece ser recomendada a proposição oferecida, como contribuição valiosíssima para a fixação dêste conceito debatido. Foi esta a conclusão a que chegou a Comissão, recomendando ao plenário a aprovação da tese, como subsídio à fixação do conceito de ato de comércio. (Palmas.)

O SR. PRESIDENTE - Está em discussão a proposição da Comissão.

O SR. FRANCISCO MACHADO - Eu pediria ao sr. relator que esclarecesse se a Comissão pede ao plenário a aprovação dos conceitos do autor da tese, ou apenas considera a tese como subsídio, não recomendando, entretanto, a adoção dos conceitos.

O SR. CAMILO MARTINS COSTA - 0 relator não recomenda a adoção dos conceitos. Apenas recomenda a tese como contribuição para a oportuna fixação do conceito de ato de comércio.

O SR. PRESIDENTE - Realmente, o professor Arecha tem uma concepção verdadeiramente revolucionária. Parece-me muito prudente a recomendação do sr. relator. Parece-me, que a tese merece um estudo mais aprofundado e demorado. A maior homenagem, muitas vêzes, que merece um trabalho não é a aprovação, mas ser motivo de meditação.

O SR. CAMILO MARTINS COSTA - Ser objeto de consideração.

O SR. PRESIDENTE - Exatamente. Submeto à consideração da Comissão. Se não houver objeções, vou considerá-la aprovada. (Pau. sa.) Aprovada. 